Article

\title{
Structure and Physicochemical Properties of Malate Starches from Corn, Potato, and Wrinkled Pea Starches
}

\author{
Miaomiao Shi ${ }^{1,2,3}{ }^{\circ}$, Yue Jing ${ }^{1}$, Liuzhi Yang ${ }^{1}$, Xianqing Huang ${ }^{4}$, Hongwei Wang ${ }^{1,2,3}$, \\ Yizhe Yan $1,2,3, *$ (D) and Yanqi Liu $1,2,3, *$ \\ 1 School of Food and Biological Engineering, Zhengzhou University of Light Industry, Zhengzhou 450002, \\ China; chengzi3090@126.com (M.S.); jy133456jy@163.com (Y.J.); 2008040@zzuli.edu.cn (L.Y.); \\ hwwang@zzuli.edu.cn (H.W.) \\ 2 Collaborative Innovation Center of Food Production and Safety, Zhengzhou 450002, China \\ 3 Henan Key Laboratory of Cold Chain Food Quality and Safety Control, Zhengzhou 450002, China \\ 4 College of Food Science and Technology, Henan Agricultural University, Zhengzhou 450002, China; \\ hxq8210@126.com \\ * Correspondence: yanyizhe@mail.ustc.edu.cn (Y.Y.); liuyanqi@zzuli.edu.cn (Y.L.); \\ Tel.: +86-135-9258-3213 (Y.Y.); +86-139-3822-8293 (Y.L.)
}

Received: 19 August 2019; Accepted: 17 September 2019; Published: 19 September 2019

check for updates

\begin{abstract}
In this study, corn, potato, and wrinkled pea starches were esterified with malic acid under high temperatures for different lengths of time. The degree of substitution (DS), granule morphology, crystal structure, gelatinization properties, and the digestibility of the malate starch were investigated. Fourier transform infrared spectroscopy (FT-IR) suggested that the malate starch showed a new infrared absorption peak near $1747 \mathrm{~cm}^{-1}$, indicating the occurrence of an esterification reaction. With an increasing treatment time, the degree of substitution (DS) of the malate starch displayed an increasing trend. Scanning electron microscopy (SEM) demonstrated a significant change in the surface structure of the starch granules. X-ray diffractometry (XRD) reflected that the crystal structure of the malate starches was destroyed. The thermogravimetric (TG) curves showed that the maximum heat loss rate of the malate starch was ahead of that of native starch, which caused the decreased degree of crystallinity. These properties of malate starch could allow it to be used for the purpose of starch modification to produce resistant starch and to provide new applications for starch.
\end{abstract}

Keywords: malic acid; starch; structure; property

\section{Introduction}

Starch is an important source of energy for the human diet and an important component of food [1]. It comes mainly from the roots, stems and seeds of cereals and potatoes [2]. Commercialized starches include native starches and modified starches. In recent years, the research focus on food grade organic acid in starch function improvement has gradually increased. Recently, research on the reaction of starch and organic acids to manufacture resistant starch in high yield has been increasingly favored by domestic and overseas scholars. Because resistant starch is low in calories and has high levels of dietary fiber, it has become a research hotspot in functional foods. Xie [3] used citric acid to react with native corn starch $\left(140^{\circ} \mathrm{C}, 7 \mathrm{~h}\right)$ to obtain $68.3 \%$ resistant starch. During this reaction, the hydroxyl group on the glucose ring in the starch chain reacted with citric acid to form a crosslinked structure derivative with a high percentage of resistant starch (RS). Hung [4] used citric acid, lactic acid, and acetic acid to react with waxy rice starch by a heat-moisture treatment (HMT) method, which increased the content of resistant starch from $30.1 \%$ to $39.0 \%$. The content of RS was significantly higher than 
that of native starch. Luo studied the acetylation of three different amylose content corn starches in sodium hydroxide solution $(20 \%, \mathrm{w} / \mathrm{w})$ as a catalytic aqueous solution and investigated the structural differences in the resulting acetylated starch derivatives [5].

Esterified starches have various applications in the field of food processing, such as in thickeners, additives, stabilizers, emulsifiers, flavoring ingredients, and binders for drying foods. There are also nonfood uses, for instance, as fillers, super disintegrants, hot melt adhesives, coatings, etc. [6]. In the medical field, esterified starches are also very useful as controlled release agents. A product of starch and fatty acids with a certain chain length could help maintain human colon function and prevent colon disease [1]. Malic acid is a healthy and nonharmful food additive. It has a soft taste and is easily soluble in many organic solvents. It is normally stable and belongs to the polycarboxylic acids in chemical structure, as does citric acid. As a food additive, malic acid has been used in food preservation, deodorization, color retention, and salt reduction, but there have been few reports on it when used as a starch modifier.

Our previous research explored the reaction mechanisms of wrinkled pea starch and malic acid to produce resistant starch as measured through nuclear ${ }^{13} \mathrm{C} \mathrm{CP/MAS} \mathrm{NMR} \mathrm{spectra,} \mathrm{FTIR,} \mathrm{etc.,}$ and simultaneously investigated the effect of HMT on the properties of esterified starch [7]. Corn, potato, and wrinkled pea starches belong to different A, B, and C crystal types, respectively. Starches of different crystal type exhibit different properties after esterification, which was meaningful for our research. It was the purpose of this paper to explore which starch was more sensitive to malic acid to give a high level of resistant starch.

In this experiment, corn, potato, and wrinkled pea starches were esterified with malic acid under high temperatures for different lengths of time. The structure, degree of substitution, physicochemical, and in vitro digestibility of malate starch were studied. The preparation of malate starch could achieve the purpose of starch modification to produce resistant starch and provide new applications for starch.

\section{Materials and methods}

\subsection{Materials}

Corn starch was purchased from Qinhuangdao Lihua Starch Co., Ltd. (Qinhuangdao, China) with $0.3 \%$ protein, $0.2 \%$ ash, $10.9 \%$ moisture, $23.2 \%$ amylose, and a little fat. Potato starch was produced by Weston Company (Qinghai, China), and it contained $0.1 \%$ protein, $0.3 \%$ ash, $15.8 \%$ moisture, $21.6 \%$ amylose, and a little fat. Wrinkled pea seeds (wild variety) were obtained from the farmers of Gansu Province in China. The wrinkled pea starch had $0.4 \%$ protein, $0.1 \%$ ash, $10.0 \%$ moisture, 30.8\% amylose, and a little fat. Malic acid was acquired from Fuchen Chemical Reagent Factory (Tianjin, China). Pancreatin from porcine pancreas (P7545, 8×USP) and amyloglucosidase from Aspergillus niger (A7095, 300 U/mL) were purchased from Sigma-Aldrich Chemical Co. (St. Louis, MO, USA). Glucose oxidase-peroxidase (GOPOD) assay kits were obtained from Megazyme International Ireland Ltd. (Wicklow, Ireland). All other chemicals and reagents were of analytical grade.

\subsection{Preparation of Malate Starch Samples}

The reaction of starch and malic acid was carried out following the method of Klaushofe [8] with appropriate modifications. Starch $(25 \%, \mathrm{w} / \mathrm{v})$ was dispersed into malic acid solution $(20 \%, \mathrm{w} / \mathrm{v})$, and the $\mathrm{pH}$ of the starch slurry was adjusted to 3 with sodium hydroxide solution $(10 \mathrm{~mol} / \mathrm{L})$. The mixture was allowed to stand at room temperature for $12 \mathrm{~h}$ to allow full penetration of starch and malic acid. The starch slurry was kept in an air oven at $45^{\circ} \mathrm{C}$ for a sufficient time to achieve a moisture content of less than $10 \%$. The sample was ground, crushed, and put into a hydration reactor at $130{ }^{\circ} \mathrm{C}$ for $2 \mathrm{~h}, 3 \mathrm{~h}, 4 \mathrm{~h}$, or $5 \mathrm{~h}$. The unreacted malic acid was washed away with deionized water several times. The starch sample was dried at room temperature. Finally, the starch was crushed, and passed through a 100 mesh standard sieve to obtain the malate starch. 


\subsection{Determination of the Degree of Substitution (DS)}

The DS of the malate starch was determined by the method of Kweon [9]. The DS was calculated from the reactive group (2-hydroxysuccinyl) of malic acid. Malate starch ( $1 \mathrm{~g}$, dry weight) was added into deionized water $(10 \mathrm{~mL})$, and then two drops of phenolphthalein indicator solution was added. The sample was titrated to the associated reddish color with $\mathrm{NaOH}(0.1 \mathrm{~mol} / \mathrm{L})$. $\mathrm{NaOH}(5 \mathrm{~mL}, 0.45 \mathrm{~mol} / \mathrm{L})$ was added into the mixture and stirred for $60 \mathrm{~min}$. Excess sodium hydroxide was neutralized with a standard hydrochloric acid solution $(0.2 \mathrm{M})$. Natural starch was used as a blank test. The results were calculated as follows [7]:

Mass fraction of malic acid substituents A:

$$
\mathrm{A} \%=\frac{\mathrm{V}_{0}-\mathrm{V}_{1} \times \mathrm{C} \times \mathrm{M} \times 100}{\mathrm{~W} \times 1000}
$$

DS of malate starch:

$$
\mathrm{DS}=\frac{162 \times \mathrm{A}}{100 \mathrm{M}-(\mathrm{M}-1) \mathrm{A}}=\frac{162 \times \mathrm{A}}{11700-116 \mathrm{~A}}
$$

$\mathrm{V}_{0}$-the volume of $\mathrm{HCl}$ solution consumed by the blank, $\mathrm{mL}$;

$\mathrm{V}_{1}$ - the volume of $\mathrm{HCl}$ solution consumed by the sample, $\mathrm{mL}$;

$\mathrm{C}$ - the exact concentration of the standard titration solution of hydrochloric acid, $\mathrm{mol} / \mathrm{L}$;

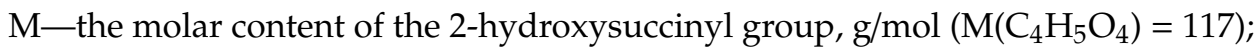

$\mathrm{W}$ - the mass of the sample, $\mathrm{g}$;

162-the relative molecular mass of glucosyl;

1000 - conversion factor.

\subsection{Scanning Electron Microscopy (SEM)}

After the starch was sprayed with gold, the SEM image was taken using a scanning electron microscope (PhilipsXL-3, HITACHI, Tokyo, Japan) at 20 KV [10].

\subsection{X-Ray Diffraction (XRD)}

The XRD patterns of starch samples were obtained by an X-ray diffractometer (Burker D8, Karlsruhe, German) at $3 \mathrm{kV}$ and $20 \mathrm{~mA}$ with $0.1542 \mathrm{~nm} \mathrm{Cu} \mathrm{K} \alpha$ radiation (Ni filter). The scanning range was $2 \theta$ values of $5-35^{\circ}$ at a $0.04^{\circ}$ step size and with a scanning rate of $4^{\circ} / \mathrm{min}$ [11]. The relative crystallinity was obtained by using the following formula:

$$
\text { Crystallinity }(\%)=\frac{I_{c}}{\left(I_{a}+I_{c}\right)} \times 100
$$

where $I_{a}$ and $I_{c}$ are the amorphous and crystalline area, respectively, on the X-ray diffractogram.

\subsection{Fourier Transform Infrared Spectroscopy (FT-IR)}

The sample and the required $\mathrm{KBr}$ were dried in an air oven at $40-50{ }^{\circ} \mathrm{C}$ for $4-5 \mathrm{~h}$ to avoid the influence of moisture before testing. FT-IR analysis of the malate starches were executed over a wave number range of $4000-400 \mathrm{~cm}^{-1}$ with a resolution of $4 \mathrm{~cm}^{-1}$ on an FT-IR instrument (Vertex70, Karlsruhe, German) The samples were scanned 64 times using the transmission method. Finally, the average value was obtained [12].

\subsection{Thermogravimetric (TG) Analysis}

The thermal stability of the malate starch sample was performed using a differential thermal analyzer (Diamond TG/DTA-A, Norwalk, America). Starch (3 mg, dry weight) was heated in an aluminum oxide pan from 30 to $600{ }^{\circ} \mathrm{C}$ with a $10{ }^{\circ} \mathrm{C} / \mathrm{min}$ heating rate and $40 \mathrm{~mL} / \mathrm{min} \mathrm{N}_{2}$ gas flow [13]. 
The temperatures at which the malate starch began to lose and completely lost water can be seen from the TG curve.

\subsection{In Vitro Starch Digestion}

In vitro digestibility of starch was evaluated using the method of Englyst [14], as modified by $\mathrm{Du}$ [15]. Starch (1 g, dry weight) with $20 \mathrm{~mL}$ of sodium acetate buffer $(0.1 \mathrm{~mol} / \mathrm{L}, \mathrm{pH} 5.2)$ was gelatinized $\left(100{ }^{\circ} \mathrm{C}\right)$ for $30 \mathrm{~min}$, and then cooled down to room temperature. An enzyme suspension $(5 \mathrm{~mL}$, pancreatin and amyloglucosidase) was added to the starch solution. The mixture was shaken in a constant temperature $\left(37^{\circ} \mathrm{C}\right)$ water bath oscillator (SHZ-82, Jinyi Instrument Technology Co., Ltd, Changzhou, China) at $150 \mathrm{r} / \mathrm{min}$ for $2 \mathrm{~h}$. Aliquots $(0.5 \mathrm{~mL}$ ) were taken at different times (20 and $120 \mathrm{~min})$ and mixed with $70 \%$ ethanol $(20 \mathrm{~mL})$ to stop enzymatic digestion. These solutions were centrifuged (3000 r/min, $10 \mathrm{~min}$ ), and the hydrolyzed glucose content of the supernatants were measured using the GOPOD kit at $510 \mathrm{~nm}$. The rapidly digested starch (RDS), slowly digested starch (SDS), and resistant starch (RS) contents were calculated using the following equations [16]:

$$
\begin{gathered}
\text { RDS }(\%)=\frac{\left(\text { Glucose }_{20 \mathrm{~min}}-\mathrm{FG}\right) \times 0.9}{\mathrm{TS}} \times 100 \% \\
\operatorname{SDS}(\%)=\frac{\left(\text { Glucose }_{120 \mathrm{~min}}-\mathrm{Glucose}_{20 \mathrm{~min}}\right) \times 0.9}{\mathrm{TS}} \times 100 \% \\
\operatorname{RS}(\%)=1-\mathrm{RDS} \%-\mathrm{SDS} \%
\end{gathered}
$$

where TS represents the weight of the starch sample; Glucose $20 \mathrm{~min}$ and Glucose ${ }_{120 \mathrm{~min}}$ represent the amount of glucose released within 20 and 120 min, respectively and FG represents the glucose content (free glucose) in the sample before hydrolysis.

\subsection{Statistical Analysis}

The data reported were the averages of triplicate determinations and the results were represented as the mean values $\pm \mathrm{SD}$ (standard deviation). Analysis of the data was performed through variance analysis (ANOVA) and significance analysis was done by Duncan's multiple range tests. Significance analysis was performed using SPSS 21.0. The level of significance was set at $p<0.05$. All the graphs were obtained using Origin 6.1 software.

\section{Results and Analysis}

\subsection{Degree of Substitution (DS) Analysis of the Malate Starch Samples}

Starches with different crystal types were reacted with malic acid for different dry heat times. Reaction time had a great impact on the DS of the malate starch. The DS values of malate starches prepared over different reaction times are shown in Figure 1. As the reaction time increased, the DS of the malate starch increased significantly. When the dry heat treatment time increased from $2 \mathrm{~h}$ to $5 \mathrm{~h}$, the DS of corn, potato, and wrinkled pea malate starch samples gradually increased from $0.455,0.424$, and 0.458 to $0.552,0.549$, and 0.544 , respectively. This was because the increased dry heat treatment time could promote malic acid more easily when combined with starch, which could increase the DS and accelerate the reaction rate. In addition, researchers indicated that the DS value of crosslinked rice starch with citric acid was shown to increase along with the concentration [17]. Within $3 \mathrm{~h}$, the esterification reactions of potato and wrinkled pea starch were basically completed, and a prolonged reaction time after this point had little effect on the esterification reaction. This was consistent with the results of Zuo [18]. After $3 \mathrm{~h}$, the reaction efficiencies of potato and pea starch tended to balance. Thereafter, the effect of reaction time on the DS was not obvious. For corn starch, the DS was increased after $3 \mathrm{~h}$. This may be due to differences in the structure and properties in different crystalline starches. 

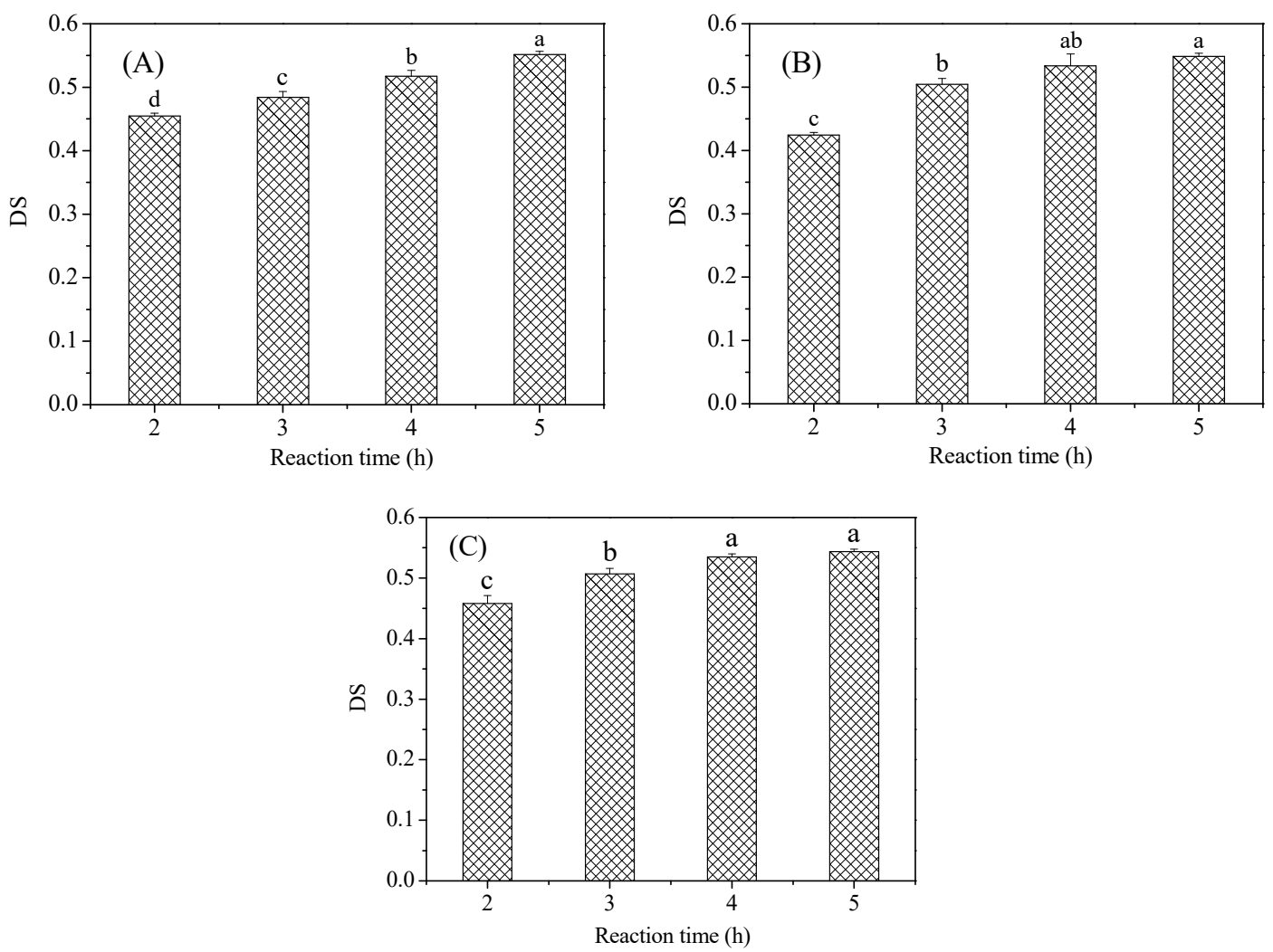

Figure 1. DS (degree of substitution) of malate starch samples: (A) Corn starch, (B) Potato starch, (C) Pea starch. Different letters in the same chart represent significant differences between different samples $(p<0.05)$.

\subsection{Scanning Electron Microscopy (SEM) of the Malate Starch Samples}

The granular morphologies of native starches and malate starches treated for different reaction times are shown in Figure 2. It can be seen that the native corn starches were a polygonal shape with a plurality of planes and edges on the surface. However, after malic acid treatment, the center of the corn starch exhibited depressions and deformations. The formation of some spots and cracks on the surfaces of wheat starch granules under citric acid treatment was also observed by Majzoobi [19]. Some starch granules adhered to each other. Deformation of esterified corn starch granules with a lower DS was reported by López-Rubio [1]. It can be seen from Figure 2 that the native potato starch granules had a smooth surface with an oval shape and a complete granule. Most of the potato starch granules were intact as the esterification reaction progressed, however, the partial granules exhibited depressions and ruptures on the surface after $4 \mathrm{~h}$ and $5 \mathrm{~h}$ of dry heat treatment time. This was consistent with previous studies on heat-moisture-treated tapioca starch by Andrade [20], who also found depressions and damage on the surfaces of starch granules. Fornal [21] observed jagged areas and ring shapes in the surface of commercial food grade esterified potato starch granules. Similar shapes were found on potato starch granules after a hydroxypropylation reaction [22]. Wrinkled pea starches were mostly flat and ellipsoidal in shape with slight wrinkles on the surface. The average granule sizes of native wrinkled pea starches were $10-40 \mu \mathrm{m}$. After the esterification reaction, more pits and wrinkles appeared on the surfaces of wrinkled pea starch granules. The granules retained their size and shape, indicating that the esterification reaction mainly happened on the surface of the starch particle. Jing found that starch granules were more sensitive to esterification if they had high amylose content ( $\geq 50 \%)$ [23]. Observation of rice starch modified with citric acid showed that the esterification reaction did not destroy the integrated structure of the starch granule [24]. After $130{ }^{\circ} \mathrm{C}$ dry heat treatment, some starch granules showed obvious changes. In the early stage of the dry heat treatment, the water inside the starch granules rapidly vaporized and volatilized. At the end of the treatment, the starch granules 
were rapidly cooled, which caused the surfaces of starch granules to collapse inward. Kawabata [25] also found that heat-moisture treatment caused depressions, cracks, and crosslinks on the surfaces of starch granules.

Corn Starch

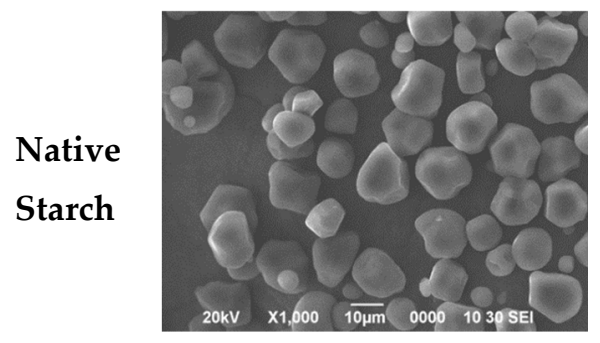

$2 \mathrm{~h}$
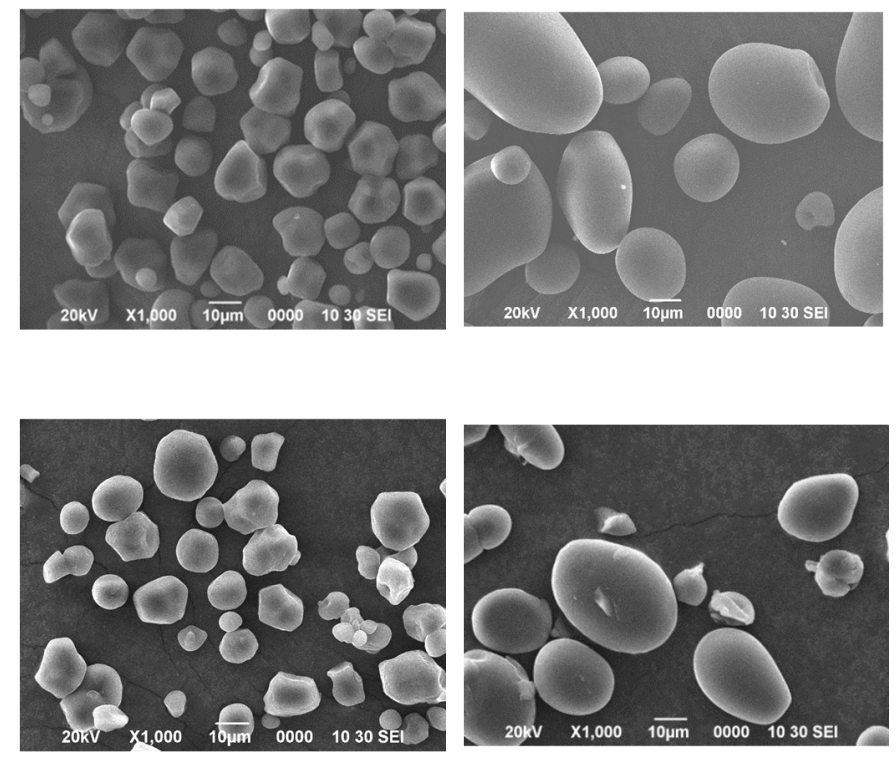

Potato Starch

Wrinkled pea starch
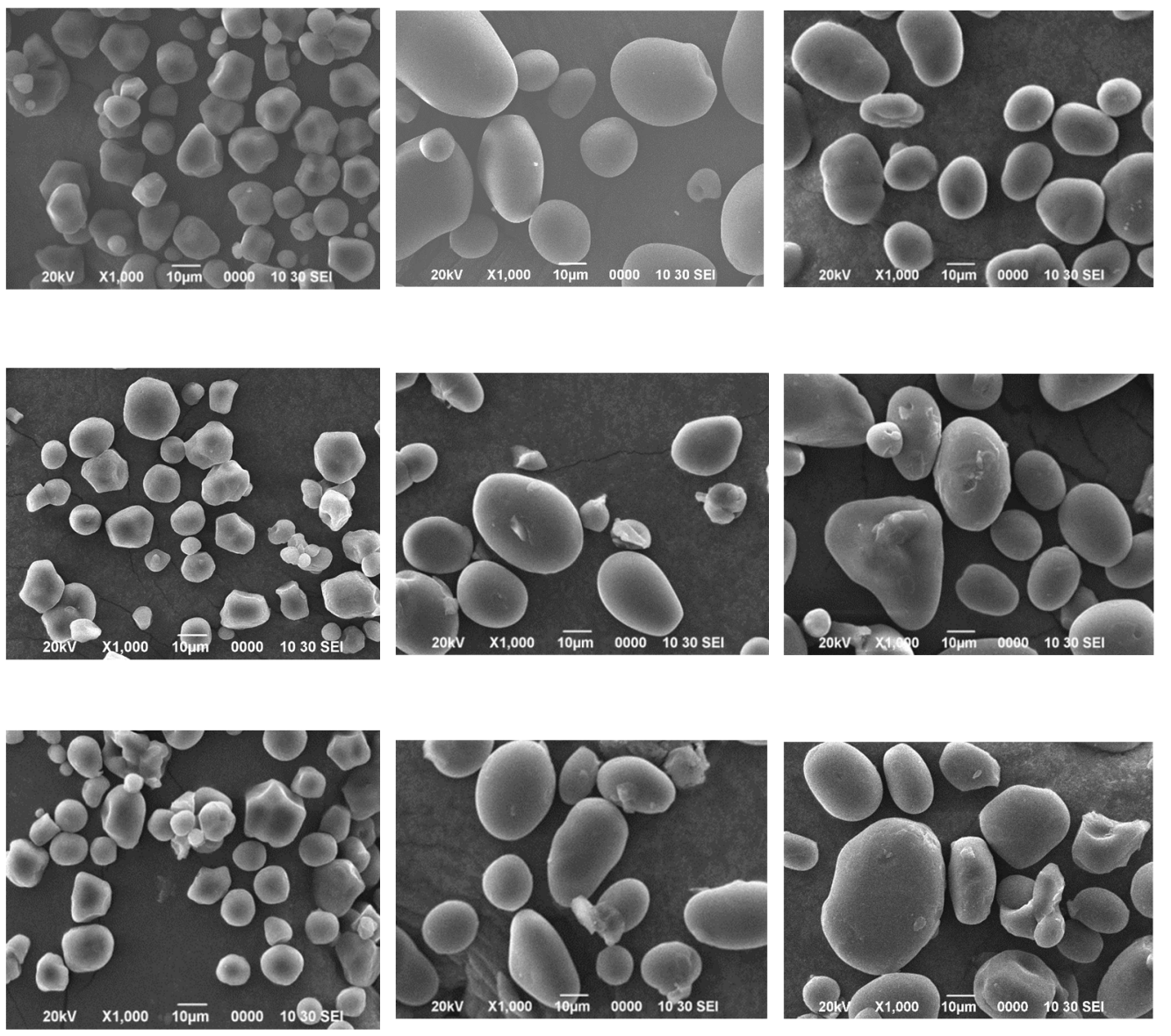

$3 \mathrm{~h}$
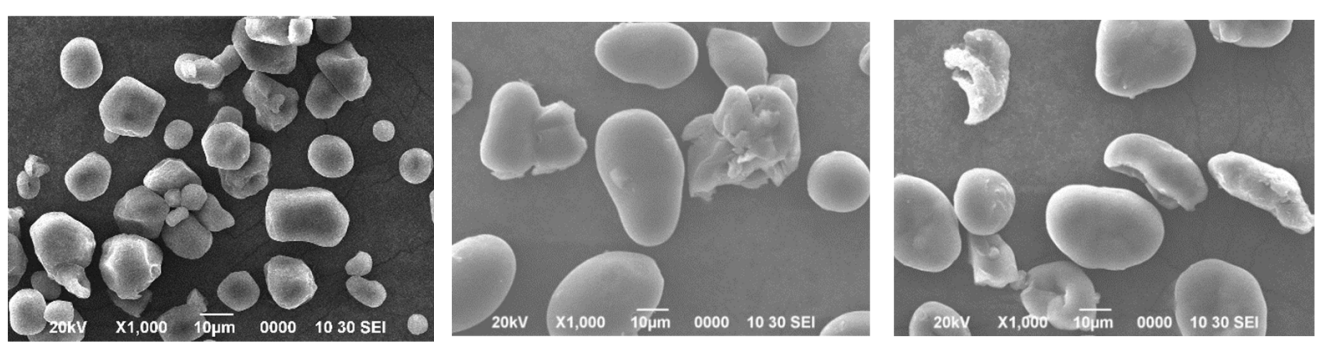

$4 \mathrm{~h}$
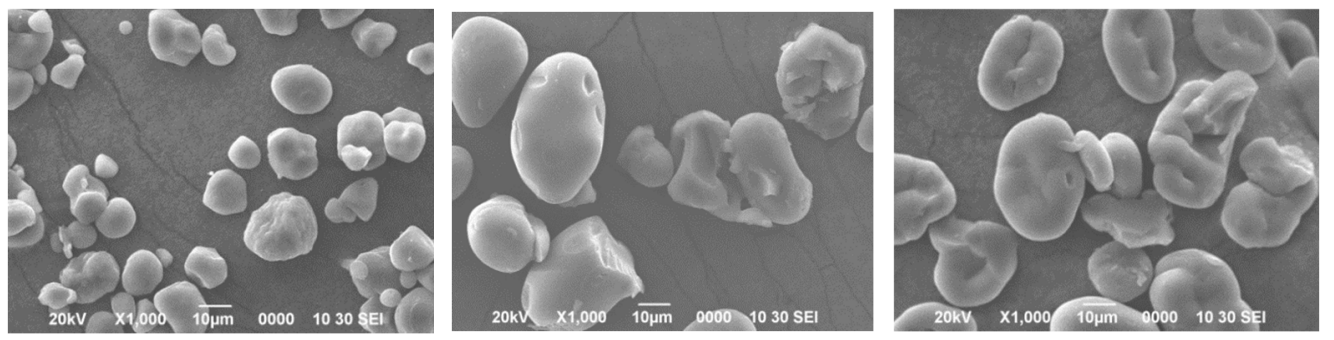

Figure 2. Scanning electron microscopy of native starch and malate starch heat treated for different lengths of time $(1000 \times)$. 
The surface of esterified starch was rougher than that of native starch, which was easier to gather together. The surface of starch granules becoming rough is a common feature of esterified starch. The aggregation of starch granules could be caused by the surface destruction of some starch granules during chemical modification [21]. It has been observed that the rise in starch granule roughness after the esterification reaction could increase the cross-linking surface area of starch granules, which could improve the adhesion of starch to starch through synthetic polymers [26]. These significant changes in starch granule morphology could have an influence on the properties of starch, which is significant for resistant starch production and application.

\subsection{X-Ray Diffraction (XRD) of the Malate Starch Samples}

The X-ray diffraction patterns of different crystalline native starches and malate starches treated for different times are shown in Figure 3. Native corn starch exhibited strong deflections at $2 \theta=15.3^{\circ}, 17.1^{\circ}$, $18.2^{\circ}$, and $23.1^{\circ}$, with a typical A-type crystalline pattern (Figure 3A). Native potato starch had major peaks at $2 \theta=5.62^{\circ}, 17.1^{\circ}, 22.3^{\circ}$, and $24.0^{\circ}$, which are typical of the B-type crystalline pattern (Figure $3 \mathrm{~B}$ ). As shown in Figure 3C, native pea starch revealed a C-type crystalline pattern. Its peaks were present at $2 \theta=5.75^{\circ}, 15.3^{\circ}, 17.3^{\circ}, 18.2^{\circ}$, and $23.3^{\circ}$. The intensity of the characteristic peaks gradually decreased as the DS increased, indicating that the crystal structure of the native starch was destroyed [27]. This is because the esterification reaction led to damage of the double helix structure, and the crystalline region of the starch was destroyed [28]. The crystalline region of starch is mainly composed of amylopectin, which is a double helix formed by intermolecular hydrogen bonds. [29]. During an esterification reaction, when the hydrogen bonds between molecules are weakened, the starch crystallinity is reduced, which causes the destruction of the original ordered crystal structure [30]. With increasing dry heat treatment time, the crystal structures of the three types of starch were subjected to different degrees of damage. Extension of the dry heat treatment time caused most of the starch hydroxyl groups to be substituted. The order of destruction was pea starch $>$ potato starch $>$ corn starch. The crystalline types of the three starches were type $A$, type $B$, and type $C$, respectively. The structure and properties were different in the three starches. The degree of crystallinity (RC) of native wrinkled pea starch was $28.64 \%$, whereas the RC of wrinkled pea starch treated for $5 \mathrm{~h}$ was approximately equal to zero. The same phenomenon was also found in potato starch treated for $5 \mathrm{~h}$. Therefore, this indicated that the malate starch showed amorphous properties [31]. This was consistent with the structures of the starch granules observed by previous scanning electron microscopy.

\subsection{Fourier Transform Infrared Spectroscopy (FT-IR) of the Malate Starch Samples}

Infrared spectroscopy is an important method used to observe any changes in the functional groups on the starch molecules. The resulting infrared spectra of the native starches and malate starches are shown in Figure 4. Traditionally, FT-IR spectroscopy of esterified starch has been used to provide qualitative evidence of the esterification reaction [32]. FT-IR showed that malate starches from the different crystalline starches presented obvious new characteristic peaks neighboring $1747 \mathrm{~cm}^{-1}$, which was related to the new ester linkages between carboxyl groups of malic acid and hydroxyl groups of starch [33]. The broadband peak centered around $3400 \mathrm{~cm}^{-1}$ was formed by the stretching vibration of the starch hydroxyl group. The decrease in the broadband peak indicated that the hydroxyl group was gradually replaced by the ester group. The data further confirmed that there was an esterification reaction between starch and malic acid. The new characteristic peaks neighboring $1747 \mathrm{~cm}^{-1}$ signal were weak in the malate starch samples with the $2 \mathrm{~h}$ dry heat reaction time level, however, with the extension of the dry heat reaction time, the intensity became stronger. The effect was most significant for malate starch treated for $5 \mathrm{~h}$, which indicated that an appropriate dry heat treatment time could promote the esterification reaction and increase the DS. 


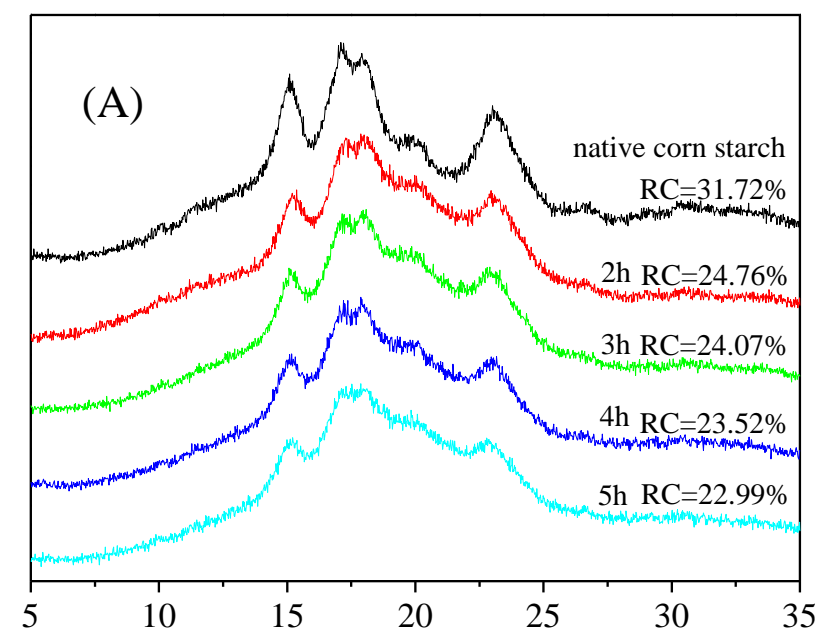

Diffraction angle $(2 \theta)$
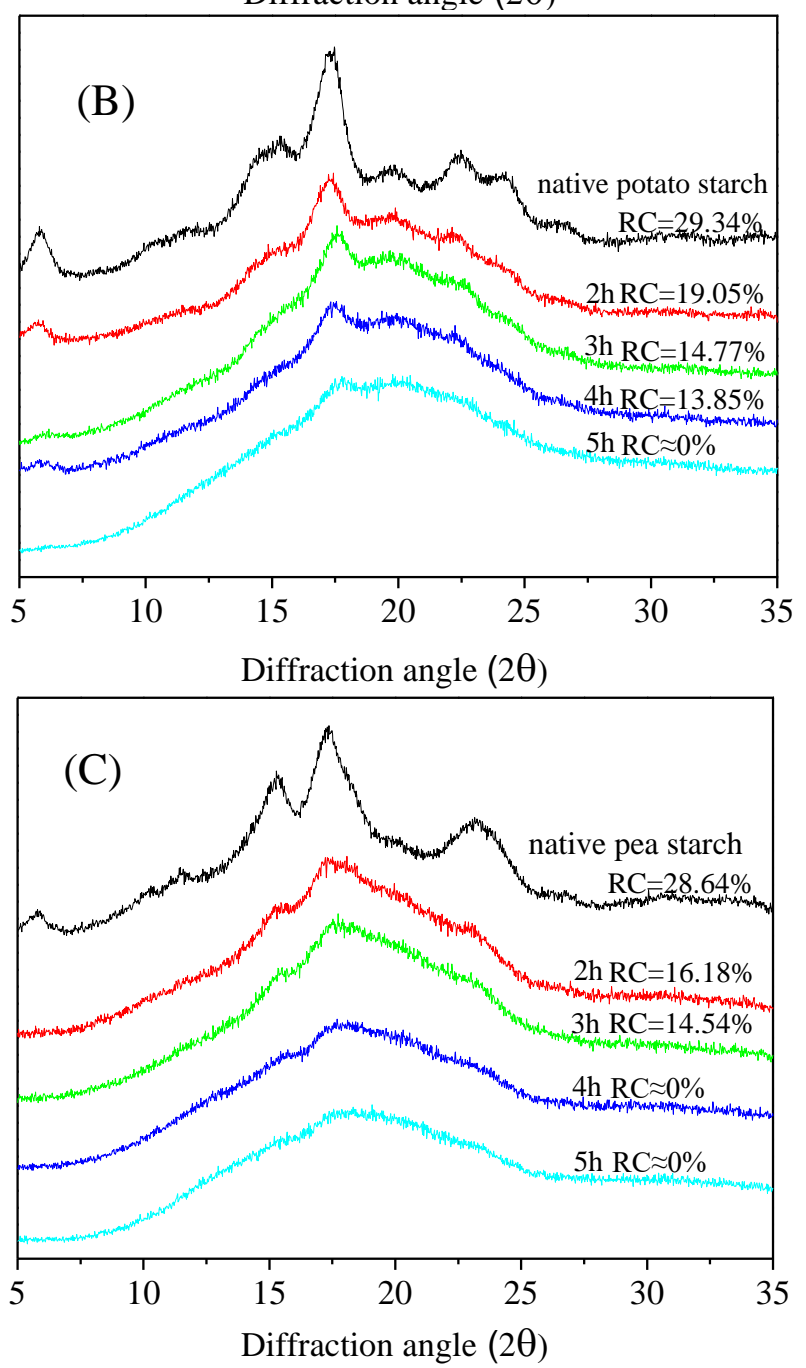

Figure 3. X-ray diffraction patterns of malate starch samples: (A) Corn starch, (B) Potato starch, (C) Pea starch. 

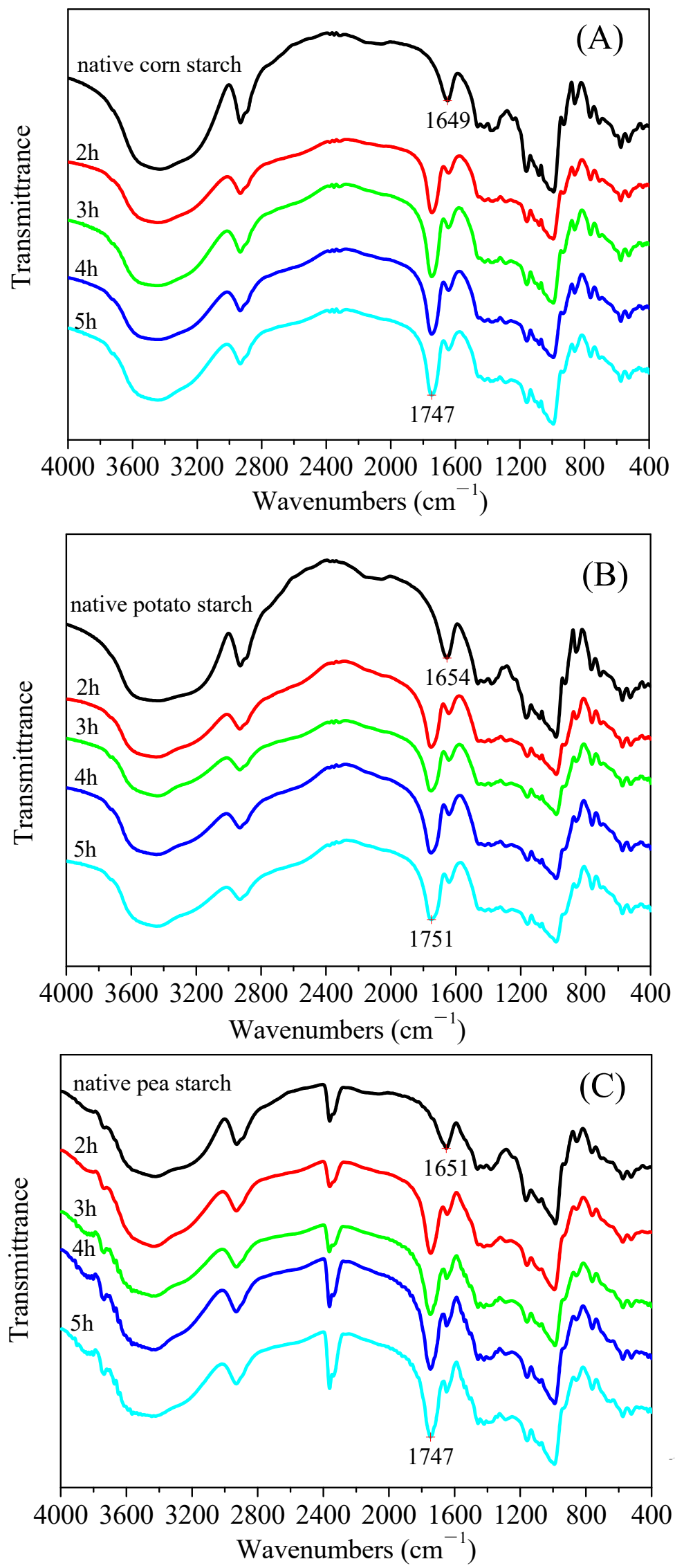

Figure 4. Fourier Transform Infrared Spectroscopy spectra of malate starch samples: (A) Corn starch, (B) Potato starch, (C) Pea starch. 


\subsection{Thermogravimetric (TG) Analysis of the Malate Starch Samples}

Thermogravimetric analysis was used to study the thermal stability and composition of materials [34]. When the samples underwent heating, cooling, and isothermal hold, TG spectra were used to detect mass loss. During heating, it can accurately measure the sample mass if the sample releases gas or if physical changes occur [35]. To investigate the thermal stability of malate starch under high temperatures for different lengths of time, thermogravimetry was used to analyze malate starch samples. Figure 5 shows the results of thermal gravimetric analysis and derivative thermogravimetric analysis (TG/DTG) for native and malate starches. As in the case of biomass pyrolysis, for each heating rate, the initial decrease in weight was due to water release. Due to the evaporation of water and the low molecular-weight substances of the malate starch, the TG curves $\left(\mathrm{A}_{1} / \mathrm{B}_{1} / \mathrm{C}_{1}\right)$ showed an initial peak (first mass loss) at $70-130{ }^{\circ} \mathrm{C}$. The mass was stable until $200{ }^{\circ} \mathrm{C}$ and the DTG curves $\left(\mathrm{A}_{2} / \mathrm{C}_{2}\right)$ showed a second peak at $250-300{ }^{\circ} \mathrm{C}$, which indicated prominent mass loss for the corn and wrinkled pea malate starches. The DTG curves $\left(B_{2}\right)$ showed a second peak at $300-325{ }^{\circ} \mathrm{C}$ for potato malate starch. The main mass loss was caused by the elimination of polyhydroxyl groups, accompanied by depolymerization and decomposition [36]. This also suggested that malic acid glycoside had been successfully esterified to starch molecular chains. The derivative thermogravimetry (DTG) curves revealed that the maximum heat loss rate of malate starch was ahead of that of native starch, which caused the decreased degree of crystallinity. It was easier to destroy the malate starch chains during heating with the lower crystallinity. Cyras [36] found that the esterified starch had lower thermal stability than the native starch owing to the low crystallinity. The x-ray diffraction data showed that the esterification reaction destroyed the starch crystallization region, and the starch molecule density was decreased, so the malate starch was easily decomposed during heating. At the same time, it was also found that the starch dissolution process increased after esterification. This was because the esterification reaction of malic acid and starch caused degradation of acidified starch. In addition, the esterification substitution was nonuniform, which led to a prolonged dissolution process.

\subsection{Digestibility Properties of the Malate Starch Samples}

The digestibility properties of the malate starch are presented in Table 1. For all the samples, as the dry heat treatment time increased, the RDS and SDS contents of the malate starches decreased significantly. The RS contents of the malate starches were higher than those of the native counterparts, and they increased with increasing dry heat treatment time. As the dry heat treatment time increased from $2 \mathrm{~h}$ to $5 \mathrm{~h}$, the RS contents of corn, potato, and wrinkled pea malate starch samples gradually increased from $15.22,21.18$, and 19.53 to $91.97,90.49$, and $95.23 \%$, respectively. Similar findings have been reported in cassava and potato esterified starches by Hung [4]. With the extension of the dry heat treatment time, the hydroxyl groups in starch molecules were replaced by malate groups. This led to the formation of the malate starch with a crosslinked structure, which prevented the hydrolysis of the amylase. During the $2 \mathrm{~h}$ dry heat treatment, the RS content of wrinkled pea starch $(71.56 \%)$ was higher than that of corn $(63.61 \%)$ and potato $(62.96 \%)$ starches. Similar results were found in the $3 \mathrm{~h}$ and $4 \mathrm{~h}$ dry heat treatment. Xie [3] believed that the difference in chemical reactions was mainly due to the differences in starch crystal type and molecular structure. Thus, the different RS content in wrinkled pea starch from those in corn and potato starches might have been due to the changes in the crystalline structure indicated in the XRD and FT-IR results analysis. These results showed that the longer the heat treatment time, the greater the amount of RS. Li [9] found that the increase in resistant starch content was due to the formation of starch citrate diester during the reaction of starch and citric acid under high temperature. The esterification reaction of starch and malic acid was similar to that of starch and citric acid. Therefore, the increased RS contents may have been due to the interaction of malic anhydrides with starch during dry heat treatment. After $3 \mathrm{~h}$, the RS contents of malate starches tended to be stable, which was consistent with the DS results analysis. 

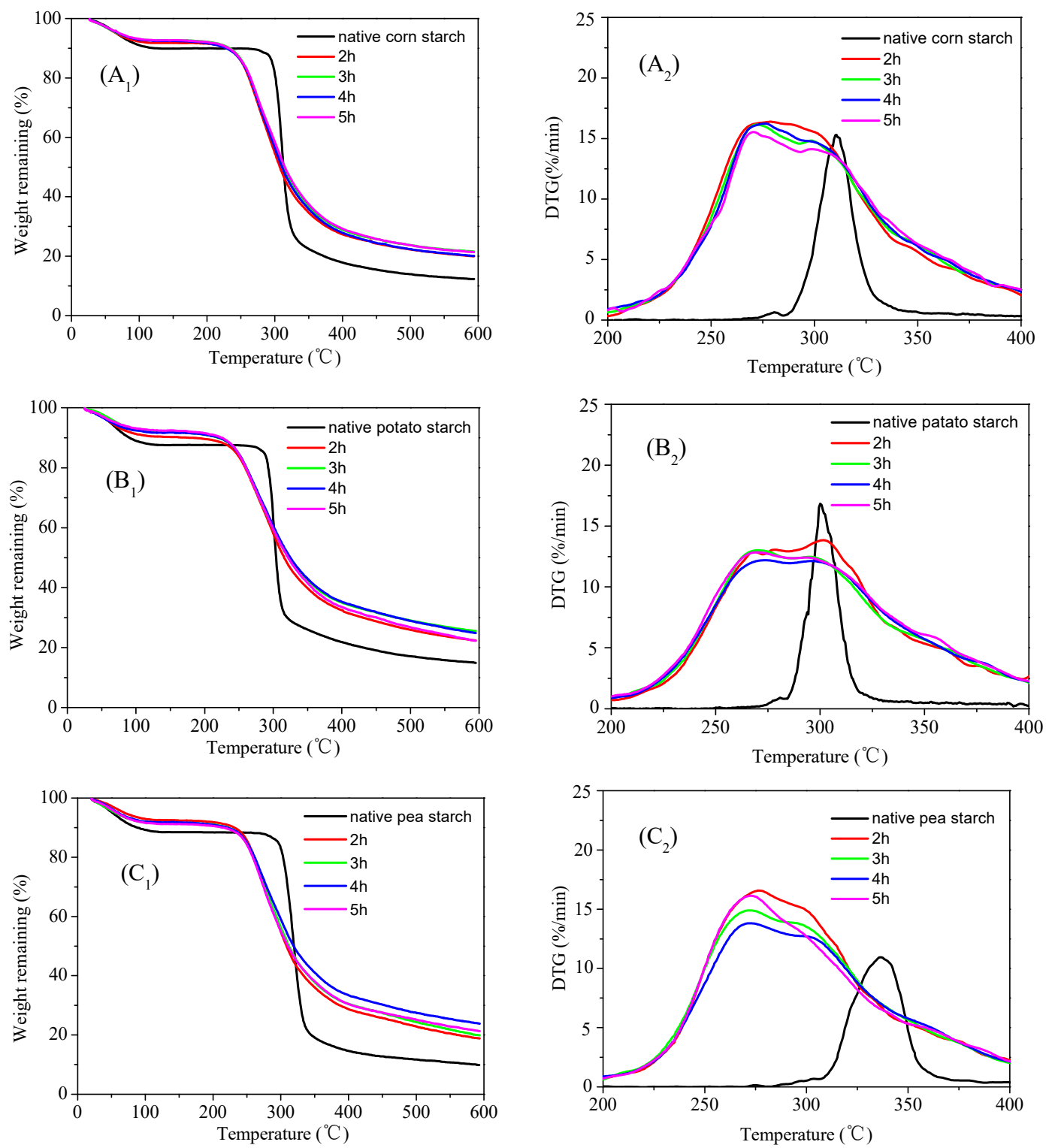

Figure 5. Thermal gravimetric analysis and derivative thermogravimetric analysis (TG/DTG) image of

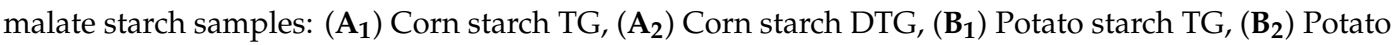
starch DTG, $\left(\mathbf{C}_{\mathbf{1}}\right)$ Pea starch TG, $\left(\mathbf{C}_{\mathbf{2}}\right)$ Pea starch DTG.

Table 1. Nutritional fractions of native and malate starch.

\begin{tabular}{cccc}
\hline Samples & RDS (\%) & SDS (\%) & RS (\%) \\
\hline Native corn Starch & $79.27 \pm 3.83^{\text {at }}$ & $5.50 \pm 4.18^{\mathrm{c}}$ & $15.22 \pm 3.53^{\mathrm{h}}$ \\
Malate corn starch-2h & $33.63 \pm 1.10^{\mathrm{d}}$ & $2.75 \pm 1.34^{\mathrm{d}}$ & $63.61 \pm 2.18^{\mathrm{f}}$ \\
Malate corn starch-3h & $19.52 \pm 0.66^{\mathrm{f}}$ & $2.22 \pm 0.28^{\mathrm{d}}$ & $78.26 \pm 0.93 \mathrm{~d}$ \\
Malate corn starch-4h & $9.61 \pm 0.77^{\mathrm{h}}$ & $0.71 \pm 0.43^{\mathrm{d}}$ & $89.68 \pm 0.43^{\mathrm{b}}$ \\
Malate corn starch-5h & $7.11 \pm 0.61^{\mathrm{ij}}$ & $0.92 \pm 0.67^{\mathrm{d}}$ & $91.97 \pm 0.20^{\mathrm{ab}}$ \\
Native potato Starch & $42.73 \pm 1.36^{\mathrm{c}}$ & $36.10 \pm 3.32^{\mathrm{a}}$ & $21.18 \pm 4.32 \mathrm{~g}$ \\
Malate potato starch-2h & $35.74 \pm 1.09^{\mathrm{d}}$ & $1.30 \pm 0.19^{\mathrm{d}}$ & $62.96 \pm 0.91^{\mathrm{f}}$ \\
Malate potato starch-3h & $16.37 \pm 0.38^{\mathrm{g}}$ & $1.27 \pm 0.47^{\mathrm{d}}$ & $82.35 \pm 0.73^{\mathrm{c}}$ \\
Malate potato starch-4h & $14.68 \pm 0.20^{\mathrm{g}}$ & $1.57 \pm 0.52^{\mathrm{d}}$ & $83.75 \pm 0.71^{\mathrm{c}}$ \\
Malate potato starch-5h & $8.71 \pm 0.68^{\mathrm{hi}}$ & $0.80 \pm 0.50^{\mathrm{d}}$ & $90.49 \pm 0.33^{\mathrm{b}}$ \\
Native pea Starch & $66.36 \pm 2.49^{\mathrm{b}}$ & $14.12 \pm 2.25^{\mathrm{b}}$ & $19.53 \pm 4.43^{\mathrm{g}}$ \\
Malate pea starch-2h & $26.88 \pm 0.51^{\mathrm{e}}$ & $1.56 \pm 0.29^{\mathrm{d}}$ & $71.56 \pm 0.80^{\mathrm{e}}$ \\
Malate pea starch-3h & $6.20 \pm 0.32^{\mathrm{jk}}$ & $0.87 \pm 0.09^{\mathrm{d}}$ & $92.93 \pm 0.31^{\mathrm{ab}}$ \\
Malate pea starch-4h & $5.05 \pm 0.27^{\mathrm{jk}}$ & $0.79 \pm 0.47^{\mathrm{d}}$ & $94.16 \pm 0.48^{\mathrm{a}}$ \\
Malate pea starch-5h & $4.02 \pm 0.25^{1}$ & $0.74 \pm 0.51^{\mathrm{d}}$ & $95.23 \pm 0.27^{\mathrm{a}}$ \\
\hline
\end{tabular}

Values are expressed as means $\pm \mathrm{SD}(\mathrm{n}=3) .{ }^{\dagger}$ Different letters in the same column indicate a significant difference at $\mathrm{P}<0.05$ within the same starch. The data are presented as the mean \pm standard deviation. RDS: rapidly digestible starch; SDS: slowly digestible starch; RS: resistant starch. 


\section{Conclusions}

The experiment above demonstrated successful esterification reactions of starch and malic acid by the dry method. The esterification reactions of malic acid with different crystalline starches caused significant changes in the structure, morphology, and gelatinization properties of malate starch. The different crystalline malate starches presented obvious characteristic peaks around $1747 \mathrm{~cm}^{-1}$-the $\mathrm{C}=\mathrm{O}$ absorption shock peak-reflecting that the starch was esterified with malic acid. With increased dry heat treatment times, the DS of malate starch showed an overall upward trend, and the starch surface structure changed significantly. Depressions, cracks, and crosslinks appeared on the surfaces of starch granules. The esterification of starch destroyed the crystal structure, especially in pea starch. The amorphous properties of malate starch were revealed. The heat loss rates and thermal stability of the malate starches were lower than those of native starch, and its dissolution process became longer. The RS contents in the malate starch samples increased significantly. Therefore, the esterification reaction of starch from different sources and malic acid by the dry heat method can effectively increase the content of resistant starch.

Author Contributions: Conceptualization, M.S.; data curation, L.Y.; funding acquisition, Y.L.; methodology, M.S.; project administration, Y.J.; resources, X.H.; software, H.W.; writing—original draft, Y.J.; writing—review and editing, Y.Y.

Funding: This research was funded by the Program for Science and Technology Innovation Talents in Universities of Henan Province (20HASTIT037), the Science and Technology Basic Research Program of Henan Province (182102110248, 182102310903, 192102110104, 192102110213), the Basic Research Plan of Higher Education School Key Scientific Research Project of Henan Province (19zx012), and the Higher Education School Young Backbone Teacher Training Program of Henan Province (2018GGJS093).

Conflicts of Interest: The authors declare no conflicts of interest.

\section{References}

1. Lopez-Rubio, A.; Clarke, J.M.; Scherer, B.; Topping, D.L.; Gilbert, E.P. Structural modifications of granular starch upon acylation with short-chain fatty acids. Food Hydrocoll. 2009, 23, 1940-1946. [CrossRef]

2. Buléon, A.; Colonna, P.; Planchot, V.; Ball, S. Starch granules: Structure and biosynthesis. Int. J. Biol. Macromol. 1998, 23, 85-112. [CrossRef]

3. Xie, X.; Liu, Q. Development and physicochemical characterization of new resistant citrate starch from different corn starches. Starch 2004, 56, 364-370. [CrossRef]

4. Hung, P.V.; Vien, N.L.; Lan Phi, N.T. Resistant starch improvement of rice starches under a combination of acid and heat-moisture treatments. Food Chem. 2016, 191, 67-73. [CrossRef] [PubMed]

5. Luo, Z.; Shi, Y. Preparation of acetylated waxy, normal, and high-amylose maize starches with intermediate degrees of substitution in aqueous solution and their properties. J. Agric. Food Chem. 2012, 60, 9468-9475. [CrossRef] [PubMed]

6. Phillips, D.L.; Liu, H.; Pan, D.; Harold, C. General application of Raman Spectroscopy for the determination of level of acetylation in modified starches. Cereal Chem. 2007, 76, 439-443. [CrossRef]

7. Shi, M.; Gao, Q.; Liu, Y. Changes in the structure and digestibility of wrinkled pea starch with malic acid treatment. Polymers 2018, 10, 1359. [CrossRef]

8. Klaushofer, H.; Berghofer, E.; Steyrer, W. Starch citrates-production and technical application properties (maize, potato). Starch 1978, 30,47-51. [CrossRef]

9. Kweon, D.K.; Choi, J.K.; Kim, E.K.; Lim, S.T. Adsorption of divalent metal ions by succinylated and oxidized corn starches. Carbohydr. Polym. 2001, 46, 171-177. [CrossRef]

10. Chen, L.; Ren, F.; Yu, X.; Zhang, Z.; Xu, D.; Tong, Q. Pasting investigation, SEM observation and the possible interaction study on rice starch-pullulan combination. Int. J. Biol. Macromol. 2015, 73, 45-48. [CrossRef]

11. Liu, Y.; Xie, H.; Shi, M. Effect of ethanol-water solution on the crystallization of short chain amylose from potato starch. Starch 2016, 68, 683-690. [CrossRef]

12. Shi, M.; Liang, X.; Yan, Y.; Pan, H.; Liu, Y. Influence of ethanol-water solvent and ultra-high pressure on the stability of amylose-n-octanol complex. Food Hydrocoll. 2018, 74, 315-323. [CrossRef] 
13. Tian, Y.; Li, Y.; Xu, X.; Jin, Z. Starch retrogradation studied by thermogravimetric analysis (TGA). Carbohydr. Polym. 2011, 84, 1165-1168. [CrossRef]

14. Englyst, H.N.; Kingman, S.M.; Cummings, J.H. Classification and measurement of nutritionally important starch fractions. Eur. J. Clin. Nutr. 1992, 46, S33-S50. [PubMed]

15. Du, S.K.; Jiang, H.; Ai, Y.; Jane, J.L. Physicochemical properties and digestibility of common bean (Phaseolus vulgaris L.) starches. Carbohydr. Polym. 2014, 108, 200-205. [CrossRef] [PubMed]

16. Lee, S.Y.; Lee, K.Y.; Lee, H.G. Effect of different $\mathrm{pH}$ conditions on the in vitro digestibility and physicochemical properties of citric acid-treated potato starch. Int. J. Biol. Macromol. 2017, 107, 1235-1241. [CrossRef] [PubMed]

17. Kim, J.Y.; Lee, Y.K.; Chang, Y.H. Structure and digestibility properties of resistant rice starch cross-linked with citric acid. Int. J. Food Prop. 2017, 20, 2166-2177.

18. Zuo, Y.; Gu, J.; Long, Y.; Qiao, Z.; Tan, H.; Zhang, Y. Synthesis and characterization of maleic anhydride esterified corn starch by the dry method. Int. J. Biol. Macromol. 2013, 62, 241-247. [CrossRef]

19. Majzoobi, M.; Beparva, P.; Farahnaky, A.; Badii, F. Effects of malic acid and citric acid on the functional properties of native and cross-linked wheat starches. Starch 2014, 66, 5-6. [CrossRef]

20. Andrade, M.M.P.; Oliveira, C.S.D.; Colman, T.A.D.; Costa, F.J.O.G.D.; Schnitzler, E. Effects of heat-moisture treatment on organic cassava starch. J. Therm. Anal. Calorim. 2014, 115, 2115-2122. [CrossRef]

21. Fornal, J.; Sadowska, J.; Błaszczak, W.; Jeliński, T.; Stasiak, M.; Molenda, M.; Hajnos, M. Influence of some chemical modifications on the characteristics of potato starch powders. J. Food Eng. 2012, 108, 515-522. [CrossRef]

22. Kaur, L.; Singh, N.; Singh, J. Factors influencing the properties of hydroxypropylated potato starches. Carbohydr. Polym. 2004, 55, 211-223. [CrossRef]

23. Hong, J.; Zeng, X.; Buckow, R.; Han, Z. Structural, thermodynamic and digestible properties of maize starches esterified by conventional and dual methods: Differentiation of amylose contents. Food Hydrocoll. 2018, 83, 419-429. [CrossRef]

24. Ma, X.; Chang, P.; Yu, J.; Stumborg, M. Properties of biodegradable citirc acid-modified granular starch/thermoplastic pea starch composites. Carbohydr. Polym. 2009, 75, 1-8. [CrossRef]

25. Kawabata, A.; Takase, N.; Miyoshi, E.; Sawayama, S. Microscopic observation and x-ray diffractometry of heat/moisture-treated starch granules. Starch 1994, 46, 463-469. [CrossRef]

26. Garg, S.; Jana, A.K. Characterization and evaluation of acylated starch with different acyl groups and degrees of substitution. Carbohydr. Polym. 2011, 83, 1623-1630. [CrossRef]

27. Diop, C.I.K.; Li, H.; Xie, B.; Shi, J. Effects of acetic acid/acetic anhydride ratios on the properties of corn starch acetates. Food Chem. 2011, 126, 1662-1669. [CrossRef] [PubMed]

28. Liu, X.; Wu, J.; Xu, J.; Mao, D. The impact of heat-moisture treatment on the molecular structure and physicochemical properties of Coix seed starches. Starch 2016, 68, 662-674. [CrossRef]

29. Altuna, L.; Herrera, M.L.; Foresti, M.L. Synthesis and characterization of octenyl succinic anhydride modified starches for food applications. A review of recent literature. Food Hydrocoll. 2018, 80, 97-110. [CrossRef]

30. Zhang, L.; Xie, W.; Zhao, X.; Liu, Y.; Gao, W. Study on the morphology, crystalline structure and thermal properties of yellow ginger starch acetates with different degrees of substitution. Thermochim. Acta 2009, 495, 57-62. [CrossRef]

31. Xu, Y.; Miladinov, V.; Hanna, M. Synthesis and characterization of starch acetates with high substitution. Cereal Chem. 2004, 81, 735-740. [CrossRef]

32. Li, M.; Xie, Y.; Chen, H.; Zhang, B. Effects of heat-moisture treatment after citric acid esterification on structural properties and digestibility of wheat starch, A- and B-type starch granules. Food Chem. 2019, 272, 523-529. [CrossRef] [PubMed]

33. Dontulwar, J.R.; Borikar, D.K.; Gogte, B.B. An esteric polymer synthesis and its characterization using starch, glycerol and maleic anhydride as precursor. Carbohydr. Polym. 2006, 65, 207-210. [CrossRef]

34. Barud, H.S.; Ribeiro, C.A.; Crespi, M.S.; Martines, M.A.U.; Dexpert-Ghys, J.; Marques, R.F.C.; Messaddeq, Y.; Ribeiro, S.J.L. Thermal characterization of bacterial cellulose-phosphate composite membranes. J. Therm. Anal. Calorim. 2007, 87, 815-818. [CrossRef] 
35. Thiebaud, S.; Aburto, J.; Alric, I.; Borredon, E. Properties of fatty-acid esters of starch and their blends with LDPE. J. Appl. Polym. Sci. 2015, 65, 705-721. [CrossRef]

36. Cyras, V.P.; Zenklusen, M.C.T.; Vazquez, A. Relationship between structure and properties of modified potato starch biodegradable films. J. Appl. Polym. Sci. 2006, 101, 4313-4319. [CrossRef] 